\section{Evolution of inequalities in mortality in Salvador, Bahia State, Brazil, 1991/2006}

\author{
Evolução das desigualdades na mortalidade em \\ Salvador, Bahia, Brasil, 1991/2006
}

\author{
${ }^{1}$ Instituto de Saúde Coletiva, \\ Universidade Federal da \\ Bahia, Salvador, Brasil. \\ Correspondence \\ S. A. Cruz \\ Instituto de Saúde Coletiva, \\ Universidade Federal da \\ Bahia. \\ Rua Basilio da Gama s/n, \\ Salvador, BA 40110-040, \\ Brasil. \\ shirleyac@uol.com.br
}

\begin{abstract}
An ecological study was carried out with the aim of analyzing the evolution of inequalities in mortality in Salvador, Bahia State, Brazil, between 1991 and 2006. The city was divided into four social strata from 95 geographic Information Zones. The variables used for social stratification were education level and income of heads of households. Crude and age-standardized mortality rates, age specific mortality rates, proportional Infant mortality and the proportional mortality ratio, were calculated for each zone and social strata. Data was obtained from Death Certificates and the Populational Census. Although differences between strata were smaller in 2000 than in 1991, they persist and are still high, ranging from $28.7 \%$ to $65.5 \%$. The differences between Information Zones were as much as 575\%. The authors discuss the shortcomings of information systems, recommending that health indicators should be estimated by social classes and pointing out the limits and possibilities of the methodology used here.
\end{abstract}

Social Inequity; Social Conditions; Mortality
Shirley Andrade Cruz 1

Ligia Maria Vieira-da-Silva 1

Maria da Conceição Nascimento Costa 1

Jairnilson Silva Paim 1

\section{Introduction}

The relationships between living conditions and health have been studied in different countries of various levels of development and with distinct health system models. Differences in mortality and morbidity between social strata and their spatial distribution may be found in a variety of countries for example the United States 1, Italy 2, Britain 3, Japan 4, Argentina 5,6 and Brazil 7,8. In those studies different health indicators were used, such as life expectancy, morbidity for cerebrovascular and neoplasia diseases, infant mortality and violence. It is these differences between and within countries that are not only avoidable but also unjust and constitute inequities ${ }^{9}$ or inequalities 10.

Most published studies provide evidence of the relationships between social inequalities and morbidity-mortality 11,12,13 although some studies do refute them 14 . A number of investigations, amongst which should be mentioned the Black Report 15 and the Whitehall Study 16 , which monitored 10,000 British civil servants over two decades, have demonstrated that the relationship between living conditions and health is not only present in the contrast between rich and poor, but is also seen in the distinct degrees of different socio-economic levels.

Brazil is the tenth most unequal country in the world in terms of income distribution, surpassed only by countries in Africa and Latin 
America. $10 \%$ of the Brazilian population appropriates $45.8 \%$ of the national income, while at the other extreme the poorest $10 \%$ hold only $0.8 \%$ of income; there are only seven other countries with a worse distribution, including Haiti (47.7\%) and Namibia (64.5\%) 17 . Although changes in the country's economy have resulted in improvements in income distribution amongst wageearners 18 , they do not seem to have been capable of reducing inequalities in mortality. Important differences in the distribution of morbidity and mortality persist both between states and within the same state $19,20,21,22$.

The equity guidelines upheld by Brazilian Unified National Health System (SUS) and initiatives that focus on the decentralization of health policies, the expansion of coverage and the development of territorial-based activities, all require the use of health indicators that are disaggregated both spatially and, above all, by groups and social classes, in order to support health policies aimed at overcoming inequities. Given Brazil's lack of an information system with indicators produced according to social strata or socio-economic variables, an analysis of the evolution of inequalities in the country's mortality rates requires the setting up of specific studies aimed both at monitoring this problem and at improving methodological techniques and strategies capable of estimating these inequalities and which are supported by the secondary databases available. Similarly, an analysis of the spatial and social distribution of mortality in Salvador, Bahia State in 1991 demonstrated the existence of profound inequalities. The difference between the mortality rate in the strata with better living conditions and those with worse living conditions varied from $43.1 \%$ to $142 \%$ which corresponds to an inequality ratio of between 1.4 and 2.4, and these differences occasionally reached $656.3 \% 23$.

To what extent have these inequalities evolved as a result of socio-economic changes and the establishment of the SUS in the decade following this analysis? In order to answer this question, this study aims to carry out a comparative analysis of the mortality distribution in the social space of Salvador city in the period between 1991 and 2006, and to describe the differences in mortality from classifications based on census data from 1991 and 2000 and Death Certificates from 1991, 1997, 2000 and 2006.

\section{Methodology}

A spatial aggregate study of the years 1991, 1997, 2000 and 2006 was carried out in Salvador, the capital of Bahia State, in the Northeast Region of
Brazil, which had 2,075,273 inhabitants in 1991 and 2,450,254 in 2000, according to the census demographics of 1991 and 2000, respectively. The units of analyses were social strata and 95 geographic information zones that make up the city's urban space and were classified according to physical-urban criteria by the Company for the Development of the Metropolitan Region of Salvador (Companhia de Desenvolvimento da Região Metropolitana de Salvador - CONDER), from an aggregation of census sectors, established by the Brazilian Institute of Geography and Statistics (Instituto Brasileiro de Geografia e estatística - IBGE).

Data sources were supplied by the Information Section of Salvador's Department of Health in the form of CD copies of the Death Certificates of municipality residents for the years 2000 and 2006, while for the years 1991 and 1997 our sources were photocopies of original Death Certificates stored at the State Health Department and filed at the Institute of Collective Health (Instituto de Saúde Coletiva - ISC) at the Bahia Federal University (Universidade Federal da Bahia - UFBA). The coding of registrations according to the respective information zones was determined by street name and neighborhood of residence recorded in the standard address section of the Death Certificates. When the address field was blank, and attempts to ascertain this information were unsuccessful, the information zones was coded as zone of information unknown (code 99), which made up $7.8 \%$ of the total analyzed for 2000 . Demographic and socio-economic information came from the census of 1991 and 2000.

The information zones were then classified selecting two preliminary individual characteristics as determinants of living conditions: economic capital and cultural capital, using the categories of analysis developed by Bourdieu 24 . The individuals and groups of individuals placed themselves within the social space principally according to the composition of their economic and cultural capital. In the first measurement, individuals situated themselves in the social space according to the global composition of their capital while in the second they did so according to the structure of their capital, in other words, this depended on the weight of different types of capital (economic and cultural). An approximation of these categories was obtained by using the variables income and level of schooling, as supplied by the census in a published study 23 .

Using the census sector data, families were classified according to the income level of the head of the household by zone of information group, thus: (1) low economic capital (LEC) without income and with an income of up to 
double the minimum wage; (2) medium economic capital (MEC) - income of between 2 and 5 times the minimum wage; (3) high economic capital (HEC) - income above 5 times the minimum wage. Each information zone was assigned to one of three strata, according to the largest proportion of heads of household with HED, MEC or LEC. The head of household's level of schooling was assessed according to the following classification: (1) low cultural capital (LCC) - up to 7 years of schooling (elementary education incomplete); (2) medium cultural capital (MCC) -8 to 14 years of study (elementary and high school education complete); (3) high cultural capital (HCC) - 15 years of schooling and above (further education, completed Masters and/or PhD degree).

Based on these criteria, each information zone was distributed in one of the three strata of economic capital and cultural capital, with respect to the highest proportion of the heads of family with HEC, MEC, or LEC and with HCC, MCC or LCC, respectively. By way of an example, the information zone number 9 included $8.3 \%$ of householders with LEC, $7.4 \%$ with MEC e $84.1 \%$ with HEC. As such, it was classified as HEC. This criterion was used for the cultural capital stratification where the same zone of information had $9.8 \%$ of heads of family with LCC, $39.9 \%$ with MCC and $50.1 \%$ with HCC, and thus it was considered as HCC. Therefore, it was classified as high social stratum (HEC/HCC) or stratum 1 because there was a predominance of householders with incomes above 5 times the minimum wage and with 15 or more years of education.

Nineteen zones of information had rates that were equivalent or had a difference of less than $10 \%$ in respect of two strata and were therefore systematically allocated half to one stratum and half to another. The classification of the zones of information led to four social strata: stratum 1 - HEC/HCC; stratum 2 - HEC/MCC; stratum 3 - LEC/MCC; and stratum 4 - LEC/LCC). A new classification was subsequently created in which the information zone that had a difference of less than $10 \%$ formed another stratum, named stratum $\mathrm{H}$ (heterogeneous).

Crude mortality rates (CMR), and Age-Standardized Mortality Rates (ASMR) were calculated for each social strata. Age standardization was calculated using the direct method and the population of Salvador in 1991 as a standard; 19 zones that had a population of less than, or equal to, 5,000 inhabitants were excluded to avoid distortions in rates and also to make a comparison with 1991. Salvador's islands, information zones 74 and 76, did not form part of the analysis. If the age of the dead person had not been recorded, we looked at the difference between date of death and of date of birth, which enabled us to fill in the gaps and to exclude only those records that did not contain these dates.

Mortality rates by stratum were also estimated for each age group $(0-4 ; 5-19 ; 20-39 ; 40-64$; $>64)$ per 100,000 inhabitants, with the exception of the 0 to 4 age group, which was calculated per 1,000 inhabitants. We also calculated the proportional infant mortality (PIM), which corresponded to the proportion of deaths of those less than one year of age, and the proportional mortality ratio (PMR) relative to the proportion of deaths of those aged 50 years and over. The relative risk was obtained by calculating the ratio between the mortality indicator of each stratum and the indicator of the stratum of better living conditions (stratum 1), here called the inequality ratio. Stratum 4 was used as a reference for the inequality ratio calculation of the PMR, where the lowest values corresponded to the worst living conditions.

The 1997 and 2006 populations were estimated applying the geometric method to the census data of 1991 and 2000, respectively. From the 1997 database of deaths, zones of information 4 and 5, 11 and 12 and 15 and 25 were aggregated, since they referred to the same neighborhoods. The zones of information for 1997 were classified using strata formed for 1991 as a reference and for 2006 we used the classifications for the year 2000 .

The data were consolidated using the Stata program version 10.0 (Stata Corp., College Station, USA) from eight initial databases with data from 1991, 1997, 2000 and 2006 entered into 53 working bases. The study proposal was submitted to and approved by the Ethics Research Committee of the ISC/UFBA.

\section{Results}

The geographical zones of information in Salvador situated in stratum 1 (best living conditions) bring together neighborhoods in which the proportion of householders with income above 5 minimum salaries ranged between $78.5 \%$ and $85.4 \%$ whilst zones located in stratum 4 , with worse conditions and which comprise the majority of the population presented variations of between $69.5 \%$ and $80.6 \%$ of the householders who have no income or an income of up to double the minimum wage.

In 2000, as compared to 1991, there was a greater allocation of information zones in strata 1 to 3 and a significant reduction of the number of zones in stratum 4 . The proportion in strata 1 , 
2,3 , and 4 in 2000 is equal to $9.3 \%, 26.7 \%, 14.7 \%$ and $49.3 \%$ respectively, while in 1991 these proportions were $9.1 \%, 19.7 \% 12.1 \%$ and $59.1 \%$, showing an increase in the number of zones of information with the best living conditions. We also noted that $36 \%$ of the zones were classified as high economic capital and $64 \%$ of low economic capital in 2000 , as against $29 \%$ of HEC and $71 \%$ of LEC in 1991. In relation to cultural capital in the strata HCC, MCC and LCC we found proportions of $9.3 \%, 41.3 \%$ and $49.3 \%$ respectively in 2000 and $9.1 \%, 31.8 \%$ and $59.1 \%$ in 1991 .

The CMR for Salvador was 5.1/1,000 inhabitants in 2000 and 5.3/1,000 in 1991, representing a variation of $3.15 \%$. During this period, in Valéria, for example, the ASMR changed from 11/1,000 inhabitants to 7.8/1,000 although it still remained one of the highest with a difference of $500 \%$ compared to that of Horto Florestal, zone 13, where the SMR was 1.3/1,000 and which was classified as HEC, with $59 \%$ of households earning more than five times the minimum wage.

Looking at the strata of living conditions, in 2000 the ASMR varied between 3.4 and 4.4 from the first stratum to the last, which represented a difference of $29.4 \%$ (Table 1). In 1991, there was a reduction in most of the strata, but not in the first (Table 2). In the period from 1991 to 2006, the evolution of ASMR declined over time in all four strata (Figure 1), with the greatest variation seen in stratum 2 (HEC/MCC) at 51.5\%. Similarly, the PMR increased in all strata (Table 1 and Table 2).

In relation to PIM by zone of information, Pituaçu, Campinas, Nordeste, Fazenda Grande, Piatã/Itapuã are amongst those localities that had the highest values. The neighborhoods of Mata Escura and Coutos are also in this group, and in 1991 they had a PIM of 25\% and 20.9\%, which by 2000 had reduced to $12.5 \%$ and $13 \%$. In 2000 the variation in this indicator reveals a linear gradient moving from 2.9 in the best stratum to 9.8 in the fourth; this is equivalent to a percentage variation of $175 \%$ and an inequality ratio of 3.3 (Table 1). Over all the years analyzed, the PIM showed growth from stratum 1 to stratum 4, with differences that varied from $273 \%$ in 1991 to $141 \%$ in 2006 (Table 2).

The mortality rate (MR) for specific age groups revealed differences that ranged between the first and the last stratum from $28,7 \%$ for the group of 0 to 4 year-olds to $65.5 \%$ for the 40 to 64 year-olds and with inequality rates of 1.2 and 1.6, respectively (Table 3 ).

The second classification, in which the urban space zones considered to be heterogeneous were brought together in a new stratum (stratum $\mathrm{H})$, demonstrates that approximately $30 \%$ of the population of Salvador is concentrated within these zones and that the differences between the stratum of best and worst living conditions persisted, with values remaining equivalent to inequalities rates. All of the indicators assessed accentuate the character of heterogeneity of this aggregate and place it between the third and fourth strata (Table 4).

\section{Discussion}

This study reveals that in the Municipality of Salvador, despite a drop in the general mortality rate between 1991 and 2000, inequalities persist in their distribution between the geographic information zones and distinct social strata, although there was a reduction in such inequalities over the period under analysis. Neighborhoods that are considered wealthy, situated in the south and along the coast, had the greatest proportion of people with high economic and cultural capital, good infrastructure and good service provision and demonstrated low general mortality, while in the peripheral neighborhoods and in those in the centre of the municipality, the mortality indicators remained high. For example, the risk of death in a neighborhood in which these indicators were considered very low (Valéria) was 5.23 times greater than in an area with the highest indicators of income and education (Graça).

Such differences in mortality between social strata reproduce the inequalities in income distribution that exist in this municipality and which are greater than those seen in states with the country's highest and lowest incomes. Residents of the Federal District earn five times more that those who live in Maranhão State, while a resident in a wealthy area in the municipality studied here receives on average 25 times more than is earned by an inhabitant in a poorer area 17. In Salvador, the Gini Index, which is an indicator of income inequality, is equal to 0.660 , greater than that of Brazil (0.580) and Lesotho (0.632). If it was a country, Salvador would have the second worst income distribution in the world 17 . Differences such as these, which demonstrate the coexistence of the least favorable socio-economic indicators with mortality, were observed during the same period in the capitals of Recife, a city in Pernambuco State and São Paulo 22,25.

The study also demonstrated that important changes have taken place in the composition of Salvador's social strata during the period under analysis. The reduction in the number of geographic information zones situated within the stratum of worst living conditions and the increase in the number of information zones 
Population, crude mortality rate (CMR), age-standardized mortality rate (ASMR), proportional infant mortality (PIM), proportional mortality ratio (PMR) and inequality ratio according to social strata. Salvador, Bahia State, Brazil, 2000.

\begin{tabular}{lcccccccc}
\hline Strata & Population & CMR & ASMR & $\begin{array}{c}\text { Inequality } \\
\text { ratio * }\end{array}$ & PIM & $\begin{array}{c}\text { Inequality } \\
\text { ratio }\end{array}$ & $\begin{array}{c}\text { PMR } \\
\text { ratio ** }\end{array}$ \\
\hline 1 & 147,672 & 5.7 & 3.4 & 1.0 & 2.9 & 1.0 & 80.5 & 1.5 \\
2 & 284,224 & 5.0 & 3.5 & 1.0 & 5.1 & 1.7 & 72.4 & 1.3 \\
3 & 438,065 & 5.7 & 4.8 & 1.4 & 7.9 & 2.7 & 62.9 & 1.2 \\
4 & $1,566,293$ & 4.6 & 4.4 & 1.3 & 9.8 & 3.3 & 51.7 & 1.0 \\
\hline
\end{tabular}

* Strata n/stratum 1;

** Strata $n /$ stratum 4;

Stratum 1: HEC/HCC (high economic capital/high cultural capital); stratum 2: HEC/MCC (high economic capital/medium cultural capital); stratum 3: LEC/MCC (low economic capital/medium cultural capital); stratum 4: LEC/LCC (low economic capital/low cultural capital).

Table 2

Age-standardized mortality rate (ASMR) by age, proportional infant mortality (PIM), proportional mortality ratio (PMR) and inequality ratio according to social strata. Salvador, Bahia State, Brazil, 2000.

\begin{tabular}{|c|c|c|c|c|c|c|c|c|}
\hline Strata & 1991 & $\begin{array}{c}\text { inequality } \\
\text { ratio }\end{array}$ & 1997 & $\begin{array}{c}\text { inequality } \\
\text { ratio }\end{array}$ & 2000 & $\begin{array}{l}\text { inequality } \\
\text { ratio }\end{array}$ & 2006 & $\begin{array}{c}\text { inequality } \\
\text { ratio }\end{array}$ \\
\hline \multicolumn{9}{|l|}{ ASMR } \\
\hline 1 & 2.9 & 1.0 & 3.4 & 1.0 & 3.4 & 1.0 & 3.3 & 1.0 \\
\hline 2 & 5.3 & 1.8 & 4.2 & 1.2 & 3.5 & 1.0 & 3.1 & 0.9 \\
\hline 3 & 4.5 & 1.6 & 5.2 & 1.5 & 4.8 & 1.4 & 4.5 & 1.4 \\
\hline 4 & 5.4 & 1.9 & 3.8 & 1.1 & 4.4 & 1.3 & 4.2 & 1.3 \\
\hline \multicolumn{9}{|l|}{ PIM } \\
\hline 1 & 3.0 & 1.0 & 0.8 & 1.0 & 2.9 & 1.0 & 2.7 & 1.0 \\
\hline 2 & 6.1 & 2.0 & 3.6 & 4.5 & 5.1 & 1.8 & 3.1 & 1.1 \\
\hline 3 & 6.2 & 2.1 & 4.8 & 6.0 & 7.9 & 2.7 & 5.9 & 2.2 \\
\hline 4 & 11.2 & 3.7 & 5.7 & 7.1 & 9.8 & 3.4 & 6.5 & 2.4 \\
\hline \multicolumn{9}{|l|}{ PMR } \\
\hline 1 & 76.0 & 1.5 & 83.2 & 1.4 & 80.5 & 1.6 & 80.6 & 1.4 \\
\hline 2 & 66.4 & 1.3 & 74.6 & 1.3 & 72.4 & 1.4 & 74.5 & 1.3 \\
\hline 3 & 68.5 & 1.3 & 68.7 & 1.2 & 62.9 & 1.2 & 65.7 & 1.1 \\
\hline 4 & 50.9 & 1.0 & 58.8 & 1.0 & 51.7 & 1.0 & 57.7 & 1.0 \\
\hline
\end{tabular}

Stratum 1: HEC/HCC (high economic capital/high cultural capital); stratum 2: HEC/MCC (high economic capital/medium cultural capital); stratum 3: LEC/MCC (low economic capital/medium cultural capital); stratum 4: LEC/LCC (low economic capital/low cultural capital).

within the other strata is indicative of improvements in the population's living conditions. Furthermore, social policies through income transfer programs and the increased monetary value of the minimum wage may have contributed to improvements in the health indicators analyzed. Although there is no evidence of a significant increase in welfare coverage in the primary health care network in the last decade, the implementation of the SUS in Salvador has enabled greater access to a variety of other forms of services. Thus, although social inequalities in mortality persist in this municipality, these factors may have contributed to the decrease observed here.

It is noticeable that the PIM and PMR indicators were most sensitive to the social variables 

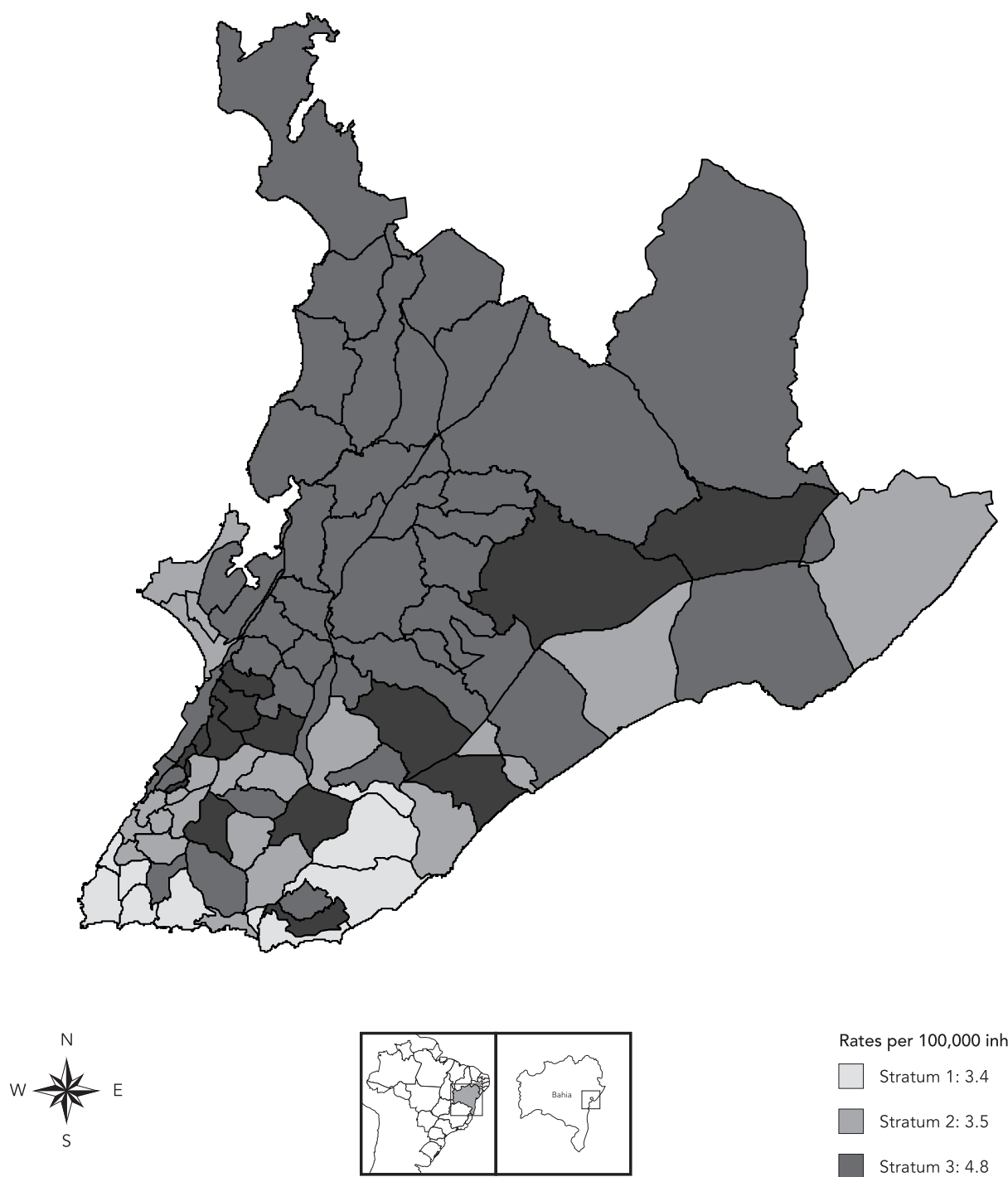

Rates per 100,000 inhabitants

Stratum 1: 3.4

Stratum 2: 3.5

Stratum 3: 4.8

Stratum $4: 4.4$

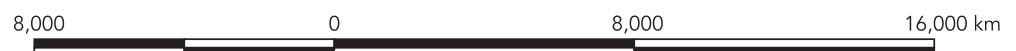

studied and revealed an increase and a reduction, respectively, with regard to the worsening of living conditions. Some of the values found here, however, require further investigation, such as, for example, the mortality rate for the 0 to 4 age group in the year 2000, which was high when compared to the other years studied.
We should provide here a justification of the use of Bourdieu's theory, given that it cannot be fully incorporated when utilized in studies of secondary data. The theory, however, guided the selection of the boundary variables of social space giving them an explanatory potential supported by a theory about social practices and their relationships to the health-illness space 23 . 
Mortality rate by age group (per 100,000 inhabitants) and inequality ratio according to social strata. Salvador, Bahia State, Brazil, 2000.

\begin{tabular}{|c|c|c|c|c|c|c|c|c|c|c|}
\hline \multirow[t]{3}{*}{ Stratum } & \multicolumn{10}{|c|}{ Age group (years) } \\
\hline & \multicolumn{2}{|c|}{$0-4$} & \multicolumn{2}{|c|}{$5-19$} & \multicolumn{2}{|c|}{$20-39$} & \multicolumn{2}{|c|}{$40-64$} & \multicolumn{2}{|c|}{$65+$} \\
\hline & $\begin{array}{c}\text { Mortality } \\
\text { ratio * }\end{array}$ & $\begin{array}{l}\text { Inequality } \\
\text { ratio ** }\end{array}$ & $\begin{array}{c}\text { Mortality } \\
\text { ratio }\end{array}$ & $\begin{array}{l}\text { Inequality } \\
\text { ratio ** }\end{array}$ & $\begin{array}{c}\text { Mortality } \\
\text { ratio }\end{array}$ & $\begin{array}{l}\text { Inequality } \\
\text { ratio ** }\end{array}$ & $\begin{array}{c}\text { Mortality } \\
\text { ratio }\end{array}$ & $\begin{array}{l}\text { Inequality } \\
\text { ratio ** }\end{array}$ & $\begin{array}{c}\text { Mortality } \\
\text { ratio }\end{array}$ & $\begin{array}{c}\text { Inequality } \\
\text { ratio ** }\end{array}$ \\
\hline 1 & 6.6 & 1.0 & 41.19 & 1.0 & 134.8 & 1.0 & 463.8 & 1.0 & 3861 & 1.0 \\
\hline 2 & 7.8 & 1.1 & 37.1 & 0.9 & 131.8 & 0.9 & 503.7 & 1.0 & 4758.6 & 1.2 \\
\hline 3 & 8.7 & 1.3 & 68.3 & 1.6 & 185.3 & 1.4 & 741.1 & 1.5 & 5204.34 & 1.3 \\
\hline 4 & 8.5 & 1.2 & 60.5 & 1.4 & 192.0 & 1.6 & 767.9 & 1.6 & 4199.6 & 1.0 \\
\hline
\end{tabular}

* Mortality rate per 1,000/under 5 years old;

** Inequality ratio $=$ Stratum/stratum 1.

Stratum 1: HEC/HCC (high economic capital/high cultural capital); stratum 2: HEC/MCC (high economic capital/medium cultural capital); stratum 3: LEC/MCC (low economic capital/medium cultural capital); stratum 4: LEC/LCC (low economic capital/low cultural capital).

\section{Table 4}

Population, crude mortality rate (CMR) of age-standardized mortality rate (ASMR), proportional infant mortality (PIM), proportional mortality ratio (PMR) and inequality ratio according to social strata. Salvador, Bahia State, Brazil, 2000.

\begin{tabular}{lcccccccc}
\hline Strata & Population & CMR & ASMR & $\begin{array}{c}\text { Inequality } \\
\text { ratio }\end{array}$ & PIM & $\begin{array}{c}\text { Inequality } \\
\text { ratio }\end{array}$ & $\begin{array}{c}\text { PMR } \\
\text { Inequality } \\
\text { ratio }\end{array}$ \\
\hline 1 & 132,284 & 5.3 & 3.3 & 1.0 & 3.2 & 1.0 & 78.7 & 1.5 \\
2 & 179,540 & 5.4 & 3.7 & 1.1 & 5.1 & 1.5 & 71.2 & 1.4 \\
3 & 133,221 & 3.2 & 2.8 & 0.8 & 7.9 & 2.4 & 60.9 & 1.2 \\
4 & $1,172,057$ & 4.6 & 4.6 & 1.3 & 10.0 & 3.0 & 49.9 & 1.0 \\
$\mathrm{H}$ & 819,152 & 5.4 & 4.5 & 1.3 & 7.9 & 2.4 & 63.1 & 1.2 \\
\hline
\end{tabular}

Stratum 1: HEC/HCC (high economic capital/ high cultural capital); stratum 2: HEC/MCC (high economic capital/medium cultural capital); stratum 3: LEC/MCC (low economic capital/medium cultural capital); stratum 4: LEC/LCC (low economic capital/low cultural capital); stratum $\mathrm{H}$ : composed of information zones with equivalent proportions or a difference of less than $10 \%$ in the distribution of economic and cultural capital.

Income and level of schooling, which were adopted here to measure the concept of economic and cultural capital, delineate possibilities of access to food, housing, knowledge and representations of diseases and risks, and of the preventive methods related to the ability to cope with these risks.

Because of the limitations in the databases utilized, this study was not able to incorporate environmental and psychological factors or factors related to the social organization of groups; and this is a significant limitation. However, the classification technique utilized in the study allowed us to join zones of information with similar characteristics and form more homogeneous strata than is possible in studies which adopt purely administrative and/or geographical criteria. Furthermore, the modification made to the technique used in 1991, which grouped the heterogeneous information zone into one unique stratum gave the remaining strata greater homogeneity, and the gradient between the strata was therefore more consistent than that obtained using the previous technique. The results obtained point to the heterogeneity of the municipality, within whose urban space developed areas, of high economic and cultural capital, sit side-byside with their opposites.

It is also important to emphasize that no information area had a majority of householders 
with an income equivalent to the rating of middle economic capital. Possibly this occurred because the cut-off for middle income (MCE), from 2 to 5 minimum wages (inclusive), was not sufficient to discriminate an average economic stratum.

ASMR was the indicator that had the lowest relationship with the social variables used, and presented higher rates in the intermediate strata than at the extremes in 1991, 1997, 2000 and 2006. The second classification, which was used for the year 2000, in which all the zones with equivalent proportions of people of a determined type of economic and/or cultural capital were grouped into stratum $\mathrm{H}$ (heterogeneous) inverted this trend to reveal an association between living conditions and this indicator. This finding demonstrated the need to obtain more homogeneous strata, either through the utilization of smaller ecological units, such as the census sector, or through linkage in future investigations between mortality databases and those of the census. The fact that the heterogeneous stratum had rates equivalent to stratum 3 may be related to an effect that some authors associ-

\section{Resumo}

Com o objetivo de analisar a evolução das desigualdades na mortalidade em Salvador, Bahia, Brasil, entre 1991 e 2006, foi realizado estudo de agregados espacial. A cidade foi dividida em 4 estratos sociais a partir das 95 zonas de informação. As variáveis utilizadas para a estratificação social foram o grau de instrução e a renda dos responsáveis pelos domicílios. Foram calculadas taxa de mortalidade geral, taxa de mortalidade padronizada por idade, mortalidade infantil proporcional e razão de mortalidade proporcional. As fontes de dados foram as Declarações de Óbito dos residentes no município e os Censos Demográficos. Apesar de as diferenças entre os estratos terem sido menores em 2000 em comparação com 1991, elas persistem e ainda são mais elevadas, variando entre $28,7 \%$ e $65,5 \%$. Essas diferenças atingiram $57,5 \%$ entre as zonas de informação. Os autores discutem as lacunas existentes nos sistemas de informação recomendando que os indicadores de saúde sejam estimados segundo as classes sociais e comentando os limites e possibilidades da metodologia utilizada.

Inequidade Social; Condições Socias; Mortalidade ate with relative income and greater ability to discriminate.

Despite the limitations of studies that use secondary mortality data, it is possible to make an approximation between geographical space and social space. These data are routinely supplied by official bodies and if utilized properly can produce a substantial amount of information.

A description of the evolution and magnitude of mortality and its distribution according to spaces and social strata may be used as a management and decision-making instrument, since existing information systems are not capable of supplying information that expresses the diversity of health status between different social groups. In this way the contribution of this study is not only related to the necessary monitoring of health inequalities in the country; it is also concerned with improvements in and the testing of classification techniques that can be adopted as technologies to support the formulation of policies and health-related activities that focus on the promotion of equity through the identification of groups and areas of greater vulnerability.

\section{Contributors}

S. A. Cruz, L. M. Vieira-da-Silva, M. C. N. Costa and J. S. Paim participated in the design and implementation of the project, the analysis and interpretation of data, the writing up of the article, a critical review of its intellectual content and approval of the final version. 


\section{References}

1. Hadden WC, Rockswold PD. Increasing differential mortality by educational attainment in adults in the United States. Int J Health Serv 2008; 38:47-61.

2. De Vogli R, Mistry R, Gnesotto R, Cornia GA. Has the relation between income inequality and life expectancy disappeared? Evidence from Italy and top industrialised countries. J Epidemiol Community Health 2005; 59:158-62.

3. Ramsay SE, Morris RW, Lennon LT, Wannamethee SG, Wincup PH. Are social inequalities in mortality in Britain narrowing? Time trends from 1978 to 2005 in a population-based study of older man. J Epidemiol Community Health 2008; 62:75-80.

4. Kagamimori S, Gaina A, Nasermosddeli A. Socioeconomic status and health in the Japonese population. Soc Sci Med 2009; 68:215-60.

5. Buchbinder M. Mortalidad infantil y desigualdad socioeconómica en la Argentina: tendencia temporal. Arch Argent Pediatr 2008; 106:212-8.

6. Alazraqui M, Mota E, Spinelli H, Guevel C. Desigualdades en salud y desigualdades sociales: un abordaje epidemiológico en un municipio urbano de Argentina. Rev Panam Salud Pública 2007; 21:1-10.

7. Boing AF, Boing AC. Mortalidade infantil por causas evitáveis no Brasil: um estudo ecológico no período 2000-2002. Cad Saúde Pública 2008; 24:447-55.

8. Vieira-da-Silva LM, Costa MCN, Paim JS, Cunha ABO, Dias IB, Guimarães ZA, et al. Brechas redutíveis de mortalidade em capitais brasileiras (19801998). Inf Epidemiol SUS 2002; 11:157-9.

9. Whitehead M. The concept and principles of equity and health. Washington DC: Pan American Health Organization; 1991.

10. Vieira-da-Silva LM, Almeida FN. Eqüidade em Saúde: uma análise crítica de conceitos. Cad Saúde Pública 2009; 25 Suppl 2:S217-26.

11. Evans RG. Producing health, consuming health care. In: Evans RG, Baren ML, Marmor TR, editors. Why are some people healthy and others not? The determinants of health of populations. New York: Aldine de Gruyter; 1994. p. 29-63.

12. Carvalho TA. Medindo desigualdades sociais na mortalidade: uma comparação de métodos no município de São Paulo [Tese de Doutourado]. Campinas: Faculdade de Ciências Médicas, Universidade Estadual de Campinas; 2004.

13. Lynch WJ, Kaplan AG, Pamuk RE, Cohen DR, Heck $\mathrm{EK}$, Balfour LJ, et al. Income inequality and mortality in Metropolitan Areas of the United States. Am J Public Health 1998; 88:1074-80.
14. Wilkinson RG, Pickett KE. Income inequality and population health: A review and explanation of the evidence. Soc Sci Med 2006; 62:1768-84.

15. Black D, Morris JN, Smith C, Townsend P. The black report. New York: Penguin/London: Pelikan; 1982.

16. Marmot M, Stansfeld S, Patel C, North F, Head J, White I, et al. Health inequality among British civil servants: the Whitehall II study. Lancet 1999; 337:1387-93.

17. Programa das Nações Unidas para o Desenvolvimento. Atlas de desenvolvimento humano da Região Metropolitana de Salvador. Brasília: Programa das Nações Unidas para o Desenvolvimento/Companhia de Desenvolvimento Urbano do Estado da Bahia/Instituto Brasileiro de Geografia e Estatística; 2006.

18. Instituto de Pesquisa Econômica Aplicada. Desigualdade de renda no Brasil: uma análise da queda recente. Brasília: Instituto de Pesquisa Econômica Aplicada; 2006.

19. Andrade SM, Soares DA, Matsuo T, Souza RKT, Mathias TAF, Iwakura MLH, et al. Condições de vida e mortalidade infantil no Estado do Paraná, Brasil, 1997/2001. Cad Saúde Pública 2006; 22:181-9.

20. Brassanesi SL, Azambuja MI, Achutti A. Mortalidade precoce por doenças cardiovasculares e desigualdades sociais em Porto Alegre: da evidência a ação. Arq Bras Cardiol 2008; 90:403-12.

21. Ishitani LH, Franco CG, Perpétuo IHO, França E. Desigualdade social e mortalidade precoce por doenças cardiovasculares no Brasil. Rev Saúde Pública 2006; 40:684-91.

22. Costa ERI. Violência contra adolescentes: diferenciais segundo estratos de condição de vida e sexo. Ciênc Saúde Coletiva 2007; 12:1193-200.

23. Vieira-da-Silva LM, Paim JS, Costa MCN. Desigualdades na mortalidade, espaço e estratos sociais. Rev Saúde Pública 1999; 33:186-197.

24. Bourdieu P. Razões práticas: sobre a teoria da ação. Campinas: Papirus; 1996.

25. Gawryszewski VP, Costa LS. Homicídios e desigualdades sociais no Município de São Paulo. Rev Saúde Pública 2005; 39:191-7.

Submitted on 15/Jun/2010

Final version resubmitted on 26/Oct/2010

Approved on 09/Nov/2010 